\title{
T LyMPhocyTE Apoptosis IN AsthmA
}

\author{
O. Potapinska, U. Demkow \\ Department of Laboratory Diagnostics and Clinical Immunology of Developmental Age, \\ Warsaw Medical University, Warsaw, Poland
}

\begin{abstract}
The paper describes the possible role of apoptosis of $\mathrm{T}$ lymphocytes in asthma pathogenesis. The authors focused on resistance against Fas-mediated programed cell death and the role of $\mathrm{Bcl}-2$ protein in impaired programed cell death process. The reports from the literature regarding the imbalance of Th1 and Th2, caused by impaired apoptosis of $\mathrm{T}$ cells, in asthma pathogenesis are reviewed.
\end{abstract}

Key words: apoptosis, asthma, T-lymphocytes

\section{INTRODUCTION}

Asthma is characterized by a reversible airway obstruction, airway inflammation and bronchial hyper-responsiveness (BHR) in response to both non-specific irritants and specific triggers such as allergens [1, 2]. Airway inflammation leads to tissue destruction and airway wall remodeling, involving epithelial disruption, smooth muscle and microvascular proliferation, basement membrane thickening, and smooth muscle hypertrophy [2]. Despite advances in the treatment of asthma, the overall mortality has not decreased significantly, while the prevalence and the severity of the disease are increasing. The prevalence of allergic asthma among children has risen drastically during the last decades, especially in Western societies [3, 4].

\section{The Role of T Lymphocytes In Asthma}

Allergic diseases are a result of disordered immunoregulation [5]. The CD4+ T lymphocytes play a major role in the pathogenesis of asthma. They cause recruitment and activation of airway eosinophils and $n$ increased $\mathrm{IgE}$ production by plasma cells $[1,2,5]$. Patients with acute severe asthma present with a significant increase in three surface proteins associated with T lymphocyte activation: IL-2R, class II histocompatibility antigen (HLA-DR), and 'very late activation' antigen, VLA-1 [5]. Recent findings in asthmatics and animal models point to a crucial role of $\mathrm{T}$ cells in mediating many manifestations of asthma, including bronchial hyperresponsiveness. The $\mathrm{T}$ cell hypothesis of asthma is based on the concept that the disease is driven and maintained by the persistence of a specialized subset of chronically activated $\mathrm{T}$ memory cells sensitized against an array of allergenic, occupational or viral antigens which home in on the lung after ap- propriate antigen exposure or viral infection $[5,6]$. The allergens induce a CD4+ T helper (Th) cell response, whereas viruses recognize CD8+ cytotoxic (Tc) cells. In the asthmatic airways, there appears to be both CD4+ and CD8+ cells with a type 2 cytokine phenotype (i.e., Th2 and Tc2 type). These cells produce: interleukin IL-5, IL-3, and granulocyte macrophage colony-stimulating factor, which recruit, mobilize, and activate eosinophils for subsequent mucosal tissue damage, and IL-4, an essential co-factor for local or generalized $\operatorname{IgE}$ production $[6,7]$. This, in turn, leads to eosinophilic desquamative bronchitis, with epithelial shedding, mucus hypersecretion and bronchial smooth muscle contraction. Although eosinophils are largely responsible for airway symptoms, their function appears to be under $\mathrm{T}$ cell control $[1,6]$.

Overactivation of CD4+ $\mathrm{T}$ cells in the peripheral blood and airway tissues is an inherent feature of asth$\mathrm{ma}$; therefore, a potent mechanism for augmenting the number of activated $\mathrm{T}$ cells in this disease would be resistance to the normally programed pathway for cell death [7-10]. There are three different mechanisms by which a cell commits suicide by apoptosis. One generated by signals arising within the cell, the second triggered by death activators binding to receptors at the cell surface: TNF-alpha, lymphotoxin, Fas ligand (FasL), and the third that may be triggered by reactive oxygen species $[4,11]$. Cell surface death receptors can transmit apoptosis signals in response to external stimuli, such as death ligands, growth factor withdrawal, or drugs. Death receptors belong to the tumor necrosis factor (TNF) receptor family and have a characteristic cysteine-rich extracellular domain and a homologous cytoplasmic 'death domain' that initiates apoptotic signaling inside the cell. These receptors can induce apoptotic cell death after ligand binding and may exert their apoptogenic effects differentially in diverse cell types, depending on downstream signaling [11].

TCR (T-cell receptor) is a protein found exclusively on T cell's surface. Its binding by a ligand is necessary either to activate the cell or to induce programed cell death. TCR interacts with peptides which belong to major histocompatibility complexes (MHC) exposed on antigen presenting cells and deliver major activation signal. The cell, however, cannot be completely activated without co-stimulation mediated by CD28 antigen. It should be pointed out that CD28 antigen 
needs interaction with its ligands, CD80 or CD86. Otherwise, the cell does not receive sufficient signal for activation and may turn to anergy (the state of unresponsiveness) and apoptosis [12].

\section{Fas-Mediated Pathway of Apoptosis}

Peripheral T cells' death requires the action of death receptor/ligand systems, particularly Fas (CD95) and Fas-ligand interaction. Pro-apoptotic signal leads to recruitment of pro-caspase- 8 to the receptor, forming the death-inducing signaling complex $[11,13]$. Upon triggering of CD95, Fas-associated death domain-containing protein and pro-caspase- 8 are recruited to the receptor, forming the death-inducing signaling complex. Once activated, caspase- 8 can initiate apoptosis of cells. The death signaling function is ensured by the presence of a cytoplasmic protein-protein interaction motif termed death domain. Binding of pro-caspase- 8 leads to its autoproteolytic activation, upon which the active enzyme is released into the cytosol [11].

Helper T lymphocytes play a key role in atopic diseases. Majority of Th0 cells in healthy individuals differentiate to Th1, whereas in atopic individuals majority of Th0 differentiate to Th2 subpopulation. Disturbed $\mathrm{T}$ helper balance is explained by impaired apoptosis of $\mathrm{T}$ cells. It is suggested that $\mathrm{T}$ lymphocytes in asthmatic patients are partially unable to get activated in antigen-mediated pathway $[5,14]$. It is also postulated that mainly Fas-triggered pathway is impaired. Apoptosis induced by $\gamma$-irradiation, mitogens, or ceramid action is not weakened [15]. The role of the number of Fas receptors on the cell surface is still under discussion. Yajaraman et al. [15] described a similar expression of Fas receptors on lymphocytes from healthy and asthmatic individuals, whereas others observed a significant decrease of Fas receptors on $\mathrm{T}$ cells' surface from asthmatic patients $[16,17]$. Spinozzi et al. [17] observed hypoexpression of Fas mRNA and surface Fas receptors on pulmonary CD3 + T lymphocytes, which may explain the persistence of inflammatory cellular infiltrates in allergic bronchial asthma. The data show a selective resistance of activated $\mathrm{T}$ cells to undergo Fas-induced apoptosis in asthmatic in comparison with non-asthmatic subjects; thereby providing initial evidence for a defect in programed cell death in the pathogenesis of asthma [15].

Because apoptosis of mature $\mathrm{T}$ cells is a powerful mechanism for deleting $T$ cells, it raises the possibility that unequal apoptosis of different effector cells may lead to preferential deletion of one subset over another $[14,18]$. Apoptosis of circulating memory/effector $\mathrm{T}$ cells confined to the selected population of cells may explain allergen-specific immune response in asthmatic individuals. Varadhachary et al. [19] pointed to Th2 apoptosis resistance. It is also postulated that the level of caspase- 8 cleavage within Th2 subpopulation is decreased in comparison with the Th1 subpopulation. Increased expression of Fas-associated phosphatase (FAP-1), which inhibits caspase cleavage, might play a key role [19]. On the other hand, Akkoc et al. [20] suggests that Th1 lymphocytes are more sensitive to Fas-mediated programed cell death than Th2 cells. The same suggestion appears in a paper by
Zhang et al. [16]. The mechanism which might be engaged in impaired apoptosis process is an increased expression of Fas and Fas ligand within Th1 lymphocytes in comparison with Th2 subpopulation. It is proposed that IFN- $\gamma$ produced by Th1 cells influences the expression of caspases and sensitizes cells to apoptosis. To confirm that hypothesis Akkoc et al. [20] showed that the absence of IFN- $\gamma$ protects Th1 lymphocytes against Fas-mediated apoptosis. De Rose et al. [21] investigated the effects of recombinant IFN- $\gamma$ on proliferation, Fas/Fas ligand (FasL) expression, and apoptosis in allergen-stimulated peripheral blood mononuclear cells obtained from atopic, asthmatic patients and non-atopic, control subjects. The addition of IFN- $\gamma$ at the start of cultures markedly inhibited the proliferative response to a specific allergen in cells from all asthmatic patients, whereas no change was observed in cells from nonatopic, control subjects. IFN- $\gamma$ induced an increase in the expression of Fas and FasL by allergen-stimulated CD4+ T cells from asthmatic patients and caused the apoptosis of these cells. A Fas-blocking monoclonal antibody prevented the inhibitory effect of IFN- $\gamma$ on allergen-induced proliferation. These results suggest that IFN- $\gamma$ inhibits the proliferation of allergen-stimulated CD4+ T cells from atopic, asthmatic patients by inducing the surface expression of Fas and FasL, which, in turn, triggers their apoptotic course [21]. The defect in IFN- $\gamma$ production involved in the allergic, immune response may, therefore, be responsible for a decrease in apoptosis of allergen-activated $\mathrm{T}$ lymphocytes in the airways of atopic, asthmatic patients [20,21].

\section{BCL-2/BAX PATHWAY OF APOPTOSIS}

The Bcl-2 (B cell lymphoma) family of genes is associated with apoptosis. The Bcl-2 protein is a suppressor of programed cell death that homodimerizes with itself and forms heterodimers with a homologous protein Bax, a promoter of cell death. The two proteins have highly similar aminoacid sequences, but are functionally opposed. The ratio of anti-apoptotic vs. proapoptotic dimers is important in determining the resistance of a cell to apoptosis [11]. Bcl-2 is an integral membrane protein located in the membranes of the endoplasmic reticulum (ER), nuclear envelope, and in the outer membranes of the mitochondria. This enhancer is very active in $\mathrm{B}$ cells. The $\mathrm{Bcl}-2$ protein suppresses apoptosis by preventing the activation of caspases that carry out the process $[7,11]$. In a normal cell, the outer membranes of its mitochondria express the $\mathrm{Bcl}-2$ protein on their surface. $\mathrm{Bcl}-2$ is bound to a molecule of the Apaf-1 protein (apoptotic protease activating factor-1). Internal damage to the cell (e.g., from reactive oxygen species) down-regulates $\mathrm{Bcl}-2$, leading to release of Apaf-1 that penetrates mitochondrial membranes, causing cytochrome $\mathrm{c}$ to leak out. The released cytochrome c and Apaf-1 bind to molecules of caspase-9 [22]. The early steps in apoptosis are reversible. Enhanced expression of $\mathrm{Bcl}-2$ inhibits both apoptotic and, in some cases, necrotic cell death in many cell types, and in response to a wide variety of inducers. Also, recent analyses of cells expressing various levels of Bcl-2 and Bax have revealed that the de- 
gree of protection against apoptosis correlates with the amount of $\mathrm{Bcl}-2$ that is free of $\mathrm{Bax}$, rather than the total amount of $\mathrm{Bcl}-2$. Bcl-2/Bax apoptosis pathway is an important mechanism limiting an inflammatory response $[23,24]$.

The amount of the $\mathrm{Bcl}-2$ protein in lymphocytes obtained from asthmatic patients is a controversial issue. Hamzaoui et al. [10] reported that lymphocytes from sputum of asthmatic patients contain more Bcl-2 protein [10], but Ying et al. [24], on the other hand, reported a decreased expression of Bcl-2 on lymphocytes isolated from bronchoalveoar lavage fluid from asthmatic patients, compared with healthy adults. A study by Abdulamir et al. [25] attempts to reconcile the controversy by indicating that the percentage of lymphocytes with $\mathrm{Bcl}-2$ expression depends on asthma severity. However, Bcl-2 expression on T lymphocytes from patients with both severe and mild asthma increases with the advancement of the disease. In general, too, Bcl-2 is found in a greater amount on lymphocytes from asthmatic patients, compared with healthy subjects, regardless of disease severity. Opposite, there is a reverse correlation between the expression of $\mathrm{Bax}$ protein and disease severity [25].

\section{SUMMARY}

The literature on the role of apoptosis of the immune cells in asthma is scarce. It is unknown why the inflammatory response cannot be turned off in atopic persons. One important mechanism in lymphocyte control is programed cell death (apoptosis), which occurs in every immune response. This mechanism seems to be impaired in asthmatic subjects. Taken together, the findings suggest that a selective resistance to Fas-dependent apoptosis reflects altered Ag-driven, accessory cell-dependent signaling, and that ineffective activation of Fas signal transduction may contribute to $\mathrm{T}$ cell-dependent inflammation in asthma. In addition, a defect in IFN- $\gamma$ formation which results in a $T$ helper cell type 2-dominated response may be responsible for a decrease in the apoptosis of allergen-activated $\mathrm{T}$ cells in asthma. Further investigations are necessary to fully explain observed abnormalities of $\mathrm{T}$ cells apoptosis in asthma.

\section{REFERENCES}

[1] Gorska K, Krenke R, Korczynski P, Kosciuch J, Domagala-Kulawik J, Chazan R. Eosinophilic airway inflammation in chronic obstructive pulmonary disease and asthma. J Physiol Pharmacol 2008; 59 Suppl 6: 261-270.

[2] Gorska K, Krenke R, Domagala-Kulawik J, Korczynski P, Nejman-Gryz P, Kosciuch J, Hildebrand K, Chazan R. Comparison of cellular and biochemical markers of airway inflammation in patients with mild-to-moderate asthma and chronic obstructive pulmonary disease: an induced sputum and bronchoalveolar lavage fluid study. J Physiol Pharmacol 2008; 59 Suppl 6: 271-283.

[3] Tai A, Volkmer R, Burton A. Prevalence of asthma symptoms and atopic disorders in preschool children and the trend over a decade. J Asthma 2009; 46: 343-346.

[4] Novershtern N, Itzhaki Z, Manor O, Friedman N, Kaminski N. A functional and regulatory map of asthma. Am J Respir Cell Mol Biol 2008; 38: 324-336.
[5] Romagnani S. The role of lymphocytes in allergic response. J Allergy Clin Immunol 2000; 105: 399-408

[6] Suarez CJ, Parker NJ, Finn PW. Innate immune mechanism in allergic asthma. Curr Allergy Asthma Rep 2008; 8: 451-459.

[7] Vignola AM, Chiappara G, Gagliardo R, Gjomarkaj M, Merendino A, Siena L, Bousquet J, Bonsignore G. Apoptosis and airway inflammation in asthma. Apoptosis 2000; 5: 473-485.

[8] Pierce JD, Pierce J, Stremmig S, Fakhari M, Clancy RL. The role of apoptosis in respiratory diseases. Clin Nurse Spec 2007; 21: 22-28.

[9] Todo-Bom A, Mota Pinto A, Alves V, Vale Pereira S, Santos Rosa M. Apoptosis and asthma in the elderly. J Investig Allergol Clin Immunol 2007; 17: 107-112.

[10] Hamzaoui A, Hamzaoui K, Salah H, Chabbou A. Lymphocytes apoptosis in patients with acute exacerbation of asthma. Mediators of Inflammation 1999; 8: 237-243.

[11] Holtzman MJ, Green JM, Jayaraman S, Arch RH. Regulation of T cell apoptosis. Apoptosis 2000; 5: 459-741.

[12] Lamb JP, James A, Carroll N, Siena L, Elliot J, Vignola AM. Reduced apoptosis of memory T-cells in the inner airway wall of mild and severe asthma. Eur Respir J 2005; 26: 265-270.

[13] Siegel RM, Fleisher TA. The role of Fas and related death receptors in autoimmune and other disease states. J Allergy Clin Immunol 1999; 103: 729-738.

[14] Akdis M, Trautmann A, Klunker S, Daigle I, Kucuksezer UC, Deglmann W, Disch R, Blaser K, Akdis CA. T helper (Th) 2 predominance in atopic diseases is due to preferential apoptosis of circulating memory/effector Th1 cells. FASEB J 2003; 17:1026-1035

[15] Jayaraman S, Castro M, O'Sullivan M, Bragdon MJ, Holtzman MJ. Resistance to Fas-mediated T cell apoptosis in asthma. J Immunol 1999; 162: 1717-1722.

[16] Zhang X, Brunner T, Carter L, Dutton RW, Rogers P, Bradley L, Sato T, Reed JC, Green D, Swain SL. Unequal death in T helper cell (Th)1 and Th2 effectors: Th1, but not Th2, effectors undergo rapid Fas/FasL-mediated apoptosis. J Exp Med 1997; 185: 1837-1849.

[17] Spinozzi F, Agea E, Fizzotti M, Bassotti G, Russano A, Droetto S, Bistoni O, Grignani F, Bertotto A. Role of Thelper type 2 cytokines in down-modulation of Fas mRNA and receptor on the surface of activated CD4(+) T cells: molecular basis for the persistence of the allergic immune response. FASEB J 1998; 12: 1747-1753.

[18] Akdis CA, Blaser K, Akdis M. Apoptosis in tissue inflammation and allergic disease. Curr Opin Immunol 2004; 16: 717-723.

[19] Varadhachary AS, Peter ME, Perdow SN, Krammer PH, Salgame P. Selective up-regulation of phosphatidylinositol 3'-kinase activity in Th2 cells inhibits caspaze- 8 cleveage at the death-inducing complex: a mechanism for Th2 resistance from Fas-mediated apoptosis. J Immunol 1999; 163: 4772-4779.

[20] Akkoc T, de Koning JA, Ruckert B, Barlan I, Akdis M, Akdis CA. Increased activation-induced cell death of high IFN- $\gamma$-producing Th1 cells as a mechanism of Th2 predominance in atopic diseases. J Allergy Clin Immunol 2008; 121: 652-658.

[21] De Rose V, Cappello P, Sorbello V, Ceccarini B, Gani F, Bosticardo M, Fassio S, Novelli F. IFN- $\gamma$ inhibits the proliferation of allergen-activated $\mathrm{T}$ lymphocytes from atopic, asthmatic patients by inducing Fas/FasL-mediated apoptosis. J Leukoc Biol 2004; 76: 423-432.

[22] Susin SA, Daugas E, Ravagnan L, Samejima K, Zamzami N, Loeffler M, Costantini P, Ferri KF, Irinopoulou T, Prévost MC, Brothers G, Mak TW, Penninger J, Earnshaw WC, Kroemer G. Two distinct pathways leading to nuclear apoptosis. J Exp Med 2000; 192: 571-580. 
[23] Ho CY, Wong CK, Ko FW Chan CH, Ho AS, Hui DS, Lam CW. Apoptosis and B-cell lymphoma-2 of peripheral blood T lymphocytes and soluble Fas in patients with allergic asthma. Chest 2002; 122: 1751-1758.

[24] Ying S, Khan LN, Meng Q, Barnes NC, Kay AB. Cyclosporin A, apoptosis of BAL T-cells and expression of Bcl-2 in asthmatics. Eur Respir J 2003; 22: 207-212.

[25] Abdulamir AS, Hafidh RR, Abubakar F, Abbas KA. Changing survival, memory cell compartment, and Thelper balance of lymphocytes between severe and mild asthma. BMC Immunol 2008; 16: 73-82.
Corresponding author:

Olga Potapinska

Department of Laboratory Diagnostics and Clinical Immunology of Developmental Age

Warsaw Medical University

Marszalkowska 24 St.

00-576 Warsaw

Poland

E-mail: olga.potapinska@wum.edu.pl 